\section{Mt Wilson Observatory}

SIR-We have recently returned from what seems all too likely to be our last observing run as guests of the Carnegie Institution with the 100 -inch telescope at Mt Wilson. California. We had 14 consecutive nights on the telescope. All of them were clear; the only cloud that we saw during that whole time was a little cirrus, which did not impede us at all, on one night. Star image diameters near one second of arc were the norm, and on several occasions we enjoyed "seeing" much better than that - the remarkable seeing for which Mt Wilson is renowned.

To experience such enviable observing conditions for such a sustained period on our final observing run heightens the irony of $\mathrm{Mt}$ Wilson Observatory being closed down ostensibly because of the deficiencies of the site. The 100-inch was shut down finally, as far as its owner the Carnegie Institution is concerned, on 26 June 1985.

Like every one of the major instruments on Mt Wilson, the 100 -inch has played a role of extraordinary distinction and significance in the progress of astronomy throughout much of this century. But it should not now be allowed to rest on its laurels. The same telescope that served Hale and Adams, Hubble and Humason, Baade, Sandage and countless others so well in the past is still in the same class as the very best of the newer telescopes, and behind its now-closed shutters it sits ready and waiting to resume the battle with the pressing problems of present-day astronomy. In this connection it is of interest to recall that observers at the 100-inch, casually viewing Saturn, were well aware of the "gramophone-record" appearance of the rings' before Voyager drew attention to that structure; but an experienced planetary observer who observed Saturn under the best conditions at the 200-inch Palomar telescope specifically asserted ${ }^{2}$ that no subdivisions exist in the rings.

The very short time-scale upon which the announcement (made barely a year ago) of the closure of Mt Wilson is being implemented has made it impossible for any other organization yet to assume financial and operational reponsibility for the observatory. Although the 100 -inch telescope is the first to close, the 60 -inch and the solar telescopes will soon follow it if they too are not taken over by other operators. The formidable researches that are being undertaken with those instruments, all of them long-term projects that would suffer severely from even a temporary interruption, are described with extraordinary honesty in the current annual reports of both the president of the Carnegie Institution and the director of the $\mathrm{Mt}$ Wilson \& Las Campanas Observatories. The juxtaposition in those reports of the current achievements of Mt Wilson Observatory and the closure of the self- same place leaves the reader altogether incredulous.

The Athay Committee, which was set up at the request of the director of $\mathrm{Mt}$ Wilson to advise on the future of the observatory, rightly refers to the "anguish" of astronomers around the world at the closure of such a distinguished observatory. The committee's report makes a strong case - actually not a difficult thing to do - for the retention of Mt Wilson in operation, and includes a recommendation that Carnegie should at least continue to run the observatory for a reasonable period until an orderly takeover by another operator can be arranged. Unfortunately, the Carnegie Institution has apparently not been able to counter reasoned argument with reasoned argument, but instead has chosen to respond with ever fiercer press releases that appear to constitute its only acknowledgement of the receipt of the report which it requested. Its position seems analogous to that of St Paul on the Damascus road before his conversion"; we devoutly hope that the parallel is completed and/or that some other institution will soon be found or set up to maintain and even enhance this great observatory. Long live Mt Wilson!

\section{The Observatories,}

Madingley Road,

Cambridge, UK

1. Livingston, W.C. Sky Telescope 49, 207 (1985)

2. Kuiper, G.P. Trans, int astr. Un. 9, 255 (1957).

3. Acts, ch. 9, vv. 1ff

\section{Soviet tests}

SIR-If your reporter meant to imply in his report on the American Association for the Advancement of Science (AAAS) meeting in Los Angeles ${ }^{1}$, that I accused the US government of lying on the question of Soviet compliance with the Yield Threshold Test Ban Treaty (YTTBT), I must take exception. I personally have no way of knowing for certain whether the assertions by some representatives of the US government ${ }^{2 \cdot 4}$ that the Soviet Union has tested over the treaty threshold of 150 kton are accurate, even less do I have any grounds for implying intent to deceive on the part of those representatives.

What was pointed out at the AAAS meeting is that the techniques for calculating unbiased estimates of the yield of underground nuclear tests have been well understood for over a decade ${ }^{5-6}$. The most recent published work that I am aware of ${ }^{7}$ concludes that within the resolution of the seismic data and analysis techniques used, the Soviet Union has not significantly exceeded the 150 kton limit. Unlike most questions of Soviet treaty compliance, this work does not depend upon classified data or analysis techniques. If the US Depart- ment of Defense (DOD) has reason to believe that this work is in error, it has a right and an obligation to demonstrate that in the open literature.

However, recent reports indicate ${ }^{4 . x}$ that work within DOD supports the finding that the Soviet Union is complying with the terms of YTTBT. If these reports are correct, DOD should make the information public. Surely no-one can have forgotten the bitter lessons of the past 20 years; in a free democratic society, the bond of trust between the government and the people is also a vital component of national security. Moreover it is unthinkable that responsible people would let false pride over a small technical error contribute to making matters any worse than they already are between the two great nuclear powers.

Allan G. Lindh

4185 Page Mill Road,

Los Altos Hills,

California 94022, USA

1. Beardsley, T. Nature 315,445 (1985)

2. US Dept of State. Security and Arms Control The Search for a More Stable Peace, 57 (Burcau of Public Affairs Washington. DC, 1983)

3. Alewine \& Bache EOS Trans. Am. Geophys. Un. 64, 193 (1983)

Science 228, $696(1985)$.

Everden \& Filson J. geophys. Res. 76, 3303-8 (1971)

6. Marshall et al. Geophys. J. R astr. Soc 57, 609-638(1979).

7. Sykes \& Cifuentes Proc, natn. Acad. Sci. U.S.A. 81, 1922 25 (1984)

8. Science 228, $1072(1985)$

\section{Prehistoric calendar}

SIR-Correspondence has recently revealed a mistake of $1^{\circ}$ in the azimuth given for the equinoctial sunset notch at the prehistoric site at Brainport Bay, Argyll (Nature 314, 158; 1985). The reduction of six solar observations taken at the Oak Bank stone backsight gave an average azimuth of the notch of $99.46^{\circ}$ west of true north and its declination of $+0^{\circ} 8^{\prime}$ was calculated from this. Somehow this azimuth became a true bearing of $261^{\circ} 32.5^{\prime}$ in the text and in Fig. 4, whereas it should of course be $260^{\circ} 32.5^{\prime}$. A fresh reduction of the same observations by a different method gives the same azimuth and a declination of $+0^{\circ} 9.6^{\prime}$

On 21 March 1985, about 26 hours after the astronomical equinox, the setting Sun was observed from the Oak Bank rock carving until it was about a solar diameter above the horizon, where it was photographed; at that point it disappeared into a bank of cloud but the disk was clearly heading directly into the notch. This of course confirms the calculations and also the inference drawn from them that we have at Brainport Bay a precise and still functioning equinoctial alignment.

Hunterian Museum,

E.W. MACKIE

The University,

Glasgow G12 8QQ, UK

Department of Astronomy,

A.E. RoY

The University,

Glasgow G128QQ, UK 